\title{
Benefits and problems of a physical training programme for asthmatic patients
}

\author{
L M Cochrane, C J Clark
}

Abstract

The clinical and physiological effects of a medically supervised, indoor physical training programme were investigated in 36 asthmatic subjects aged 16-40 years. After clinical evaluation, lung function assessment, and progressive incremental exercise testing subjects were randomly allocated to control and training groups. The measurements were repeated after a six week run in period and after a further three months in which those in the training group underwent an indoor training programme. The measurements made at three months were compared with those at the end of the run in period. There was no significant change in anthropometric characteristics, blood lipid profiles, or the provocative concentration of histamine causing a $20 \%$ fall in $\mathrm{FEV}_{1}$ (histamine $\mathbf{P C}_{20}$ ) in the group who underwent training. After training there were significant increases in mean maximal oxygen uptake $\left(\mathrm{ml} \mathrm{kg}^{-1} \mathrm{~min}^{-1}\right)$ from 23 (5) to $28(6)$, oxygen pulse ( $\mathrm{ml} /$ beat) from $8 \cdot 8$ $(2.3)$ to $10.8(2.4)$, and anaerobic threshold (1/min) from $1.11(0.27)$ to 1.38 $(0 \cdot 33)$. These changes were significantly greater in the group undergoing training than in the control group. There was also a significant fall in breathlessness scores (Borg ratings), blood lactate, carbon dioxide output, and minute ventilation during submaximal exercise in the training group, with no change in the control group. The subject's motivation, the initial level of fitness, and the symptom score at the time of training were the most important factors influencing improvements in cardiorespiratory fitness. Thus submaximal physical exercise of controlled intensity, sustained for three months, produced significant improvements in fitness and cardiorespiratory performance that should be advantageous to the exercising asthmatic patient. The availability of medical supervision throughout the exercise programme appears to have contributed to the successful outcome.

Regular physical exercise is actively encouraged now as part of developing a "healthy lifestyle." Normal individuals wishing to take advantage of the potential health benefits or wishing simply to pursue exercise as a rec- reational activity have a wide range of sports and activities from which to choose. Asthmatic patients, however, for whom there is a negative relation between severity of asthma and capacity to exercise, have more problems in participating in sport safely and effectively. ${ }^{2}$ This negative relation and the unnecessary restriction of sporting activities in children with asthma have been recognised for some time. ${ }^{3}$ There has been an attempt to remedy these problems through better education of patients, ${ }^{4}$ with advice to use a beta selective agonist before exercise $e^{5}$ and to avoid conditions apt to produce exercise induced asthma, and encouragement of swimming. ${ }^{6}$ Nevertheless a recent study $^{7}$ showed reduced cardiorespiratory fitness in adults with asthma who were uncertain about their physical capabilities. In that study the asthmatic patients had sufficient ventilatory reserve to suggest that endurance training could be tolerated at a work intensity adequate to permit improvements in fitness. The present study has piloted a carefully controlled programme of exercise training under medical supervision in a group of patients with asthma of moderate severity and has evaluated the benefits in terms of (1) cardiorespiratory fitness, as this has been shown to improve in normal individuals following a similar regimen; $;^{8}$ (2) the ventilatory and metabolic adaptations occurring during submaximal exercise; (3) the effects on breathlessness during exercise; and (4) changes in disease severity, including non-specific bronchial responsiveness, about which there have been conflicting reports. ${ }^{10-16} \mathrm{We}$ have also tried to identify which factors determine whether an individual is successful in achieving the training goals.

\section{Methods}

PATIENTS

The study subjects consisted of 36 young adults (14 male, 22 female), aged $16-40$ years, with chronic asthma of mild to moderate severity as defined by a requirement for regular prophylactic treatment and reproducible airways obstruction when treatment was withdrawn. All patients were taking aerosolised sympathomimetic agents. Fifteen had also been prescribed inhaled sodium cromoglycate and 21 corticosteroid preparations for inhalation. Two patients were dependent on long term oral steroids. All were non-smokers and free from any concomitant illness. Further characterisation of the subjects was obtained by chemical 
and exercise challenge testing. In all cases the provocative concentration of histamine causing a $20 \%$ fall in $\mathrm{FEV}_{1}\left(\mathrm{PC}_{20}\right)$ was less than $8 \mathrm{mg} /$ $\mathrm{ml}$ according to the method described by Hargreave et $a l,{ }^{17}$ and 30 of the 36 patients fulfilled criteria for exercise induced asthma. ${ }^{18}$

\section{MEASUREMENTS}

Patients were asked to refrain from taking bronchodilators for six hours before testing. Baseline spirometry and flow-volume analysis were performed with a dry rolling seal spirometer (System 5000 IV, Gould Electronics) The measurements were repeated after administration of salbutamol $(5 \mathrm{mg}$ in $1 \mathrm{ml}$ ) via a Wright mini nebuliser. Progressive incremental exercise ${ }^{19}$ was performed on an electronically braked bicycle ergometer 10 minutes after repeat dynamic spirometry. The work load was increased by $18-25$ watt increments at one minute intervals, while the subject was pedalling at a frequency of $40-60$ cycles $/ \mathrm{min}$, until he or she was exhausted (System 9000 IV, Gould Electronics).

Heart rate, respiratory frequency, tidal volume, minute ventilation $(\dot{V} E)$, and mixed expired concentrations of carbon dioxide and oxygen were measured continuously to allow calculation of oxygen consumption $\left(\mathrm{V}_{2}\right)$ and carbon dioxide production $\left(\dot{\mathrm{V}}_{\mathrm{CO}}\right)$. A dyspnoea index ${ }^{20}$ was obtained by expressing minute ventilation as a percentage of maximum voluntary ventilation (postbronchodilator $\mathrm{FEV}_{1} \times$ 35). Maximum heart rate was predicted from the formula $210-0.65 \times$ age (years) ${ }^{21}$ Oxygen pulse was defined as oxygen consumption per heart beat ( $\mathrm{ml} /$ beat). Ventilatory anaerobic threshold was determined from the $\dot{\mathrm{VE}} / \mathrm{VOO}_{2}$ plot by three independent observers, using the method of Wasserman et al. ${ }^{22}$ Before exercise a cannula was placed in the brachial vein and thereafter $3 \mathrm{ml}$ blood samples were withdrawn for estimation of venous lactate ${ }^{23}$ (Clandon 23L lactate analyser). At least five samples were taken while the subject was resting and blood was withdrawn at approximately two minute intervals throughout the exercise period and into the recovery period. During exercise subjects were instructed to estimate their sense of breathlessness according to a Borg scale. ${ }^{24}$ This is essentially a category scale in which simple verbal expressions describing increasing degrees of effort expenditure relating to exercise are linked to numbers. Patients were free to select numbers on this scale and after the initial reading each subject communicated any change in rating by hand signals and the corresponding work loads were immediately recorded by an observer. Care was taken to instruct subjects only to score breathlessness and to ignore other sensory stimuli such as leg fatigue. Transcutaneous oxygen tension was measured throughout exercise (IL $301 \mathrm{Tm}$ monitor).

\section{STUDY DESIGN}

Initial evaluation consisted of a clinical history and examination, measurement of skinfold thickness according to the method of Durnin et $a l^{25}$ for estimation of percentage body fat, lung function assessment, and progressive incremental exercise testing. A fasting blood sample was taken for determining cholesterol and lipoprotein concentrations. The patients were then randomly allocated to either the training or the control group. A six week run in period preceded training. Subjects recorded daily peak flow readings and symptom scores throughout the study.

For the control group participation was limited to attendance at educational sessions designed to encourage a greater understanding and to improve self management of their asthma. The training group attended similar but separate meetings, which also included a description of the main features and principles of the training programme. Individual motivation within the training group was assessed during the run in period by the medical supervisor, who graded it according to a five point scale ranging from 1 (poorly motivated) to 5 (highly motivated). This motivational assessment scored: adequate attendance $(1=$ yes, 0 $=$ no); satisfactory completion of daily diary cards ( $1=$ yes, $0=$ no); enthusiastic attitude to training $(1=$ yes, $0=$ no); substantial impact of asthma on capacity for daily activities as judged by the patient ( $1=$ yes, $0=$ no); and the observer's assessment of the patient's interest in participation after the educational sessions ( 1 $=$ good, $0=$ poor). Lung function and exercise evaluation were repeated at the end of the six weeks.

\section{TRAINING PROGRAMME}

The three month indoor training programme was carefully defined in terms of frequency, duration, intensity, progression, and mode of physical activity. The optimum duration and frequency of exercise were set at 30 minutes three times a week, during which the subjects had a target heart rate $75 \%$ of the predicted maximum heart rate (measured and recorded by Sport Tester PE2000). ${ }^{26}$ Medical supervision was provided during all hospital training sessions. Patients were instructed to use a beta agonist inhaler before each exercise session. Audio tape instructions for home use were available for patients unable to attend any of the hospital sessions, though attendance at the hospital was encouraged. Each session consisted of a warm up period, followed by 30 minutes of varied aerobic exercises, including cycling, jogging, and "aerobics." Patients then cooled down with a mixture of light callisthenics and stretching exercises designed to improve muscle strength and joint flexibility. Subjects kept a training log that detailed the number of hospital and home sessions attended, the time spent exercising, and a symptom score for each particular training day. For this subjects were asked to consult their daily diary cards and give an approximate aggregate score, ranging from 0 (no symptoms) to 4 (severe symptoms). (Details of the training programme are available from Dr L M Cochrane, department of respiratory medicine, Hairmyres Hospital, Glasgow.) 
Table 1 Mean (SD) anthropometric data, blood cholesterol, and baseline function and geometric mean $P C_{20}$ (range) before and after the study

\begin{tabular}{|c|c|c|c|c|}
\hline & \multicolumn{2}{|c|}{ Subjects undergoing training ( $n=18$ ) } & \multicolumn{2}{|c|}{ Control subjects ( $n=18$ ) } \\
\hline & Before & After & Before & After \\
\hline 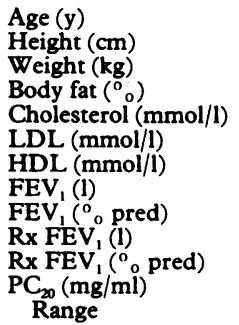 & $\begin{array}{cl}27 & (7) \\
166 & (10) \\
68 & (12) \\
30 & (5) \\
5.4 & (1 \cdot 1) \\
3 \cdot 2 & (1 \cdot 2) \\
1.7 & (0.4) \\
2.58 & (0.68) \\
76 & (12) \\
2.89 & (0.81) \\
85 & (16) \\
0.067 & \\
0.016-0.377\end{array}$ & $\begin{array}{cl}68 & (12) \\
29 & (5) \\
5.3 & (1.1) \\
2.9 & (0.9) \\
1.6 & (0.3) \\
2.97 & (0.69)^{\star} \\
87 & (15)^{\star} \\
3.21 & (0.71)^{\star} \\
95 & (13)^{\star} \\
0.077 \\
0.014-1.35\end{array}$ & $\begin{array}{cl}28 & (8) \\
169 & (9) \\
68 & (9) \\
25 & (7) \\
5.3 & (1 \cdot 1) \\
3.3 & (1.0) \\
1.5 & (0.3) \\
2.94 & (0.67) \\
82 & (14) \\
3.18 & (0.68) \\
89 & (14) \\
0.301 & \\
0.015-3.23\end{array}$ & $\begin{array}{cl}67 & (10) \\
25 & (7) \\
5.2 & (1.1) \\
3.1 & (0.9) \\
1.7 & (0.4)^{\star} \\
3.13 & (0.80) \\
88 & (21) \\
3.32 & (0.76) \\
94 & (20) \\
0.198 \\
0.017-5.65\end{array}$ \\
\hline
\end{tabular}

${ }^{\star} \mathrm{p}<0.01$ (paired $t$ test); see Knudson et al. ${ }^{27}$

Cholesterol-total blood cholesterol; LDL-low density lipoprotein; HDL—high density lipoprotein; Rx FEV $-F E V_{1}$ after $5 \mathrm{mg}$ salbutamol; $\mathrm{PC}_{20}$-provocative concentration (of histamine) causing a $20 \%$ fall in $\mathrm{FEV}_{1}$.

\section{STATISTICAL ANALYSIS}

Student's $t$ test was used to investigate differences between control and training groups and a paired $t$ test for comparison of measurements made before and after the study period within each group. A comparison of the mean changes at the end of the training period in anthropometric values, blood cholesterol, lung function, and exercise measurements in the training and the control group was also performed with Student's $t$ test. Histamine $\mathrm{PC}_{20}$ values were log transformed before analysis. A $p$ value of $<0.05$ was considered significant.

As the physiological measurements made during exercise depend on several variables, including age, sex, weight, and height, multiple regression analysis was used to compare the training and control groups after adjustment for these variables and also to determine which factors contributed most to the improvement in $\dot{\mathrm{V}}_{2} \max$ within the training group. The magnitude of linear association between pairs of continuous variables was measured with the Pearson's coefficient of correlation. Submaximal analysis was carried out as follows: (1) $\dot{\mathrm{V}}_{2}$ was plotted against $\dot{\mathrm{V}} \mathrm{E}, \dot{\mathrm{V}} \mathrm{CO}_{2}$, and lactate concentration for each subject, and a line of best fit for each relationship was determined for each plot. (2) From the line of best fit values for $\dot{V E}, \dot{V} \mathrm{CO}_{2}$, and lactate were calculated at five submaximal work loads, representing 20,40 , 60,80 , and $90^{\circ}$ of the pretraining $\dot{\mathrm{V}}_{2} \max$ for that individual. The training and control groups were compared in terms of these values before and after the study period by paired $t$ test.

A paired $t$ test was used to compare the mean $\mathrm{VO}_{2}$ (expressed as a percentage of the predicted maximum) at each Borg level before and after the study period for the training and control groups separately.

\section{Results}

During the study period, nine of the 36 study subjects (six of those undergoing training and three of the control subjects) had their treatment altered. Seven were changed from inhaled sodium cromoglycate to an inhaled steroid and two patients had, the dose of inhaled steroid increased. Anthropometric data, blood cholesterol and lipoproteins values, and lung function data for the control and training groups are summarised in table 1 . No significant difference in any of the pre-study measurements between the two groups was detected by univariate or multivariate analysis. There was an improvement in mean (SD) $\mathrm{FEV}_{1}$ (pretreatment and post-treatment) in both groups after the study period, which was significant $(p<0.01)$ in the training group. There was no significant difference between the mean change in $\mathrm{FEV}_{1}$ of $0.38(0.48)$ litres in the training group and $0.19(0.53)$ litres in the control group. There was also no difference when change in $\mathrm{FEV}_{1}$ was expressed as a percentage of the predicted normal value. Histamine $\mathrm{PC}_{20}$ was unchanged for the two groups.

Table 2 Mean (SD) maximal cardiorespiratory performance data for subjects in the study before and after the study

\begin{tabular}{|c|c|c|c|c|c|c|}
\hline \multirow[b]{3}{*}{ 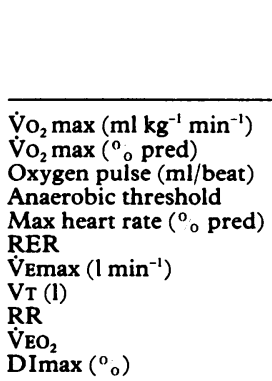 } & \multicolumn{2}{|c|}{ Subjects undergoing training $(n=18)$} & \multicolumn{4}{|c|}{ Control subjects ( $n=18)$} \\
\hline & Before & After & \multicolumn{2}{|c|}{ Before } & \multicolumn{2}{|l|}{ After } \\
\hline & $\begin{array}{cl}23 \cdot 0 & (4 \cdot 7) \\
62 & (10) \\
8 \cdot 8 & (2 \cdot 3) \\
1 \cdot 11 & (0 \cdot 27) \\
92 & (5) \\
1 \cdot 26 & (0 \cdot 12) \\
59 & (15) \\
1.93 & (0 \cdot 69) \\
32 & (5) \\
38 & (4) \\
60 & (13)\end{array}$ & $\begin{array}{ll}28 \cdot 4 & (6 \cdot 0) \ddagger \\
76 & (13) \ddagger \\
10 \cdot 8 & (2 \cdot 4) \ddagger \\
1 \cdot 38 & (0 \cdot 33) \ddagger \\
92 & (6) \\
1 \cdot 21 & (0 \cdot 11) \\
66 & (16) \ddagger \\
2 \cdot 12 & (0 \cdot 67)^{\star} \\
32 & (5) \\
35 & (4)^{\star \star} \\
60 & (14)\end{array}$ & $\begin{array}{l}25 \cdot 9 \\
63 \\
10 \cdot 0 \\
1 \cdot 24 \\
90 \\
1 \cdot 29 \\
63 \\
1 \cdot 98 \\
32 \\
37 \\
63\end{array}$ & $\begin{array}{l}(6 \cdot 7) \\
(8) \\
(2 \cdot 7) \\
(0 \cdot 29) \\
(8) \\
(0 \cdot 13) \\
(18) \\
(0 \cdot 44) \\
(5) \\
(6) \\
(16)\end{array}$ & $\begin{array}{l}25 \cdot 0 \\
60 \\
10 \cdot 0 \\
1 \cdot 15 \\
88 \\
1 \cdot 24 \\
58 \\
1 \cdot 94 \\
30 \\
35 \\
56\end{array}$ & $\begin{array}{l}(5 \cdot 9) \\
(7) \\
(2 \cdot 7) \\
(0 \cdot 26)^{\star} \\
(8)^{\star} \\
(0 \cdot 14) \\
(14)^{\star} \\
(0 \cdot 49) \\
(5) \\
(6) \\
(18)\end{array}$ \\
\hline
\end{tabular}

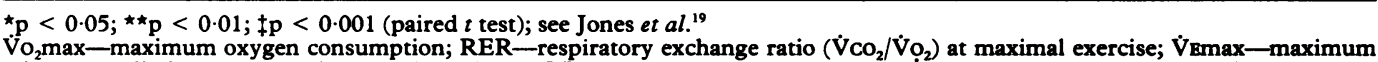
$\mathrm{V} \mathrm{O}_{2} \mathrm{max}$-maximum oxygen consumption; $\mathrm{RER}$-respiratory exchange ratio $\left(\mathrm{V}_{\mathrm{CO}_{2}} / \mathrm{Vo}_{2}\right)$ at maximal exercise; $\mathrm{VEmax}-\mathrm{maximum}$
minute ventilation; $\mathrm{VT}$-maximum tidal volume; $\mathrm{RR}$-maximum respiratory rate; $\mathrm{VEO}_{2}$ - ventilatory equivalent for oxygen at minute ventilation; $\mathrm{VT}$-maximum tidal volume; $\mathrm{RR}$-maximum respiratory rate; $\mathrm{VEO}_{2}$
maximal exercise $\left(\mathrm{VE} / \mathrm{Vo}_{2}\right)$; DImax - dyspnoea index at maximal exercise (VEmax/MVV). 
Figure 1 Relation of mean (SEM) blood lactate ( $\mathrm{mmol} / \mathrm{l}$ ), carbon dioxide production $\left(\dot{V} \mathrm{CO}_{2}\right.$ $\mathrm{ml} / \mathrm{min}$ ), and minute ventilation $\left(\dot{V} E, l \mathrm{~min}^{-1}\right)$ to oxygen consumption

( $\dot{V}_{\mathrm{O}_{2}}$, expressed as ${ }^{\circ}$ of initial $\mathrm{VO}_{2}$ max) before (O) and after (O) the study period for the training and control groups.

${ }^{\star} p<0.05 ; \star \star p<0.01$ $\star \star \star p<0.001$ (before $v$ after the study).
MAXIMAL EXERCISE PERFORMANCE

The cardiorespiratory performance at peak exercise for the patients undergoing training and the controls is shown in table 2. The training group showed a highly significant increase in all three "cardiovascular fitness" variables-that is, $\dot{V} o_{2} \max$, maximum oxygen pulse, and anaerobic threshold. VEmax (1/min) increased in the training group from $58.8(14.8)$ to $66.1(15.5)(\mathrm{p}<0.001)$, with an increase in tidal volume at peak exercise (litres) from 1.93 $(0.69)$ to $2.12(0.67) ; p<0.01$. The respiratory rate was unchanged. The ventilatory equivalent for oxygen ( $\mathrm{VEO}_{2}$ max) was reduced (from 38 (4) to $34(4) ; p<0.01$ ) in the training group but not in the controls. There was no change in the maximum dyspnoea index in either group. These changes in maximal exercise performance over the study period differed significantly between the training and control groups
Blood lactate $(\mathrm{mmol} / \mathrm{l})$

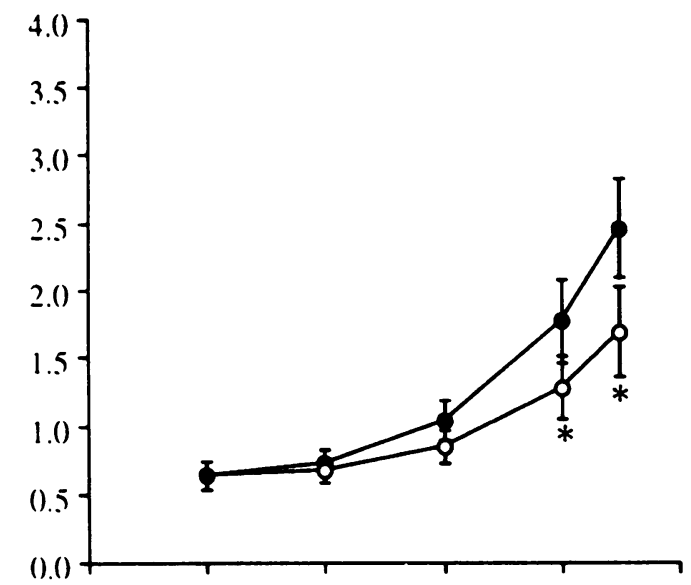

$\dot{\mathrm{V}} \mathrm{CO}_{2}(\mathrm{ml} / \mathrm{min})$

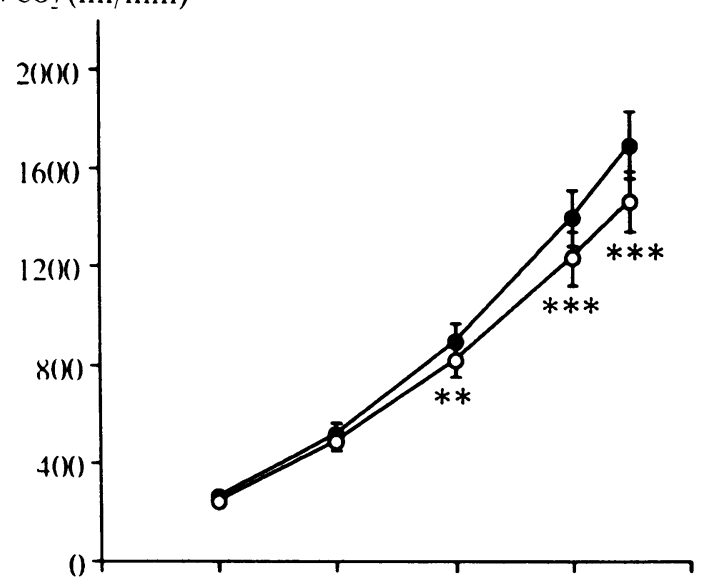

$\dot{V} \mathrm{E}(1 / \mathrm{min})$

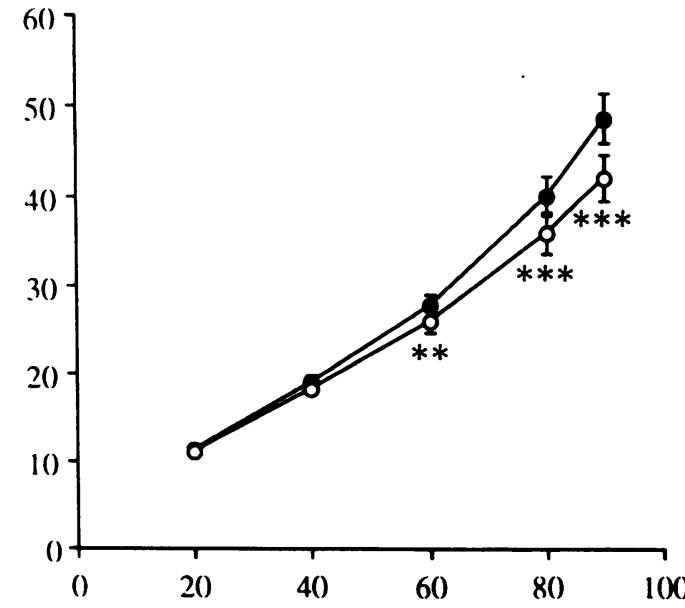

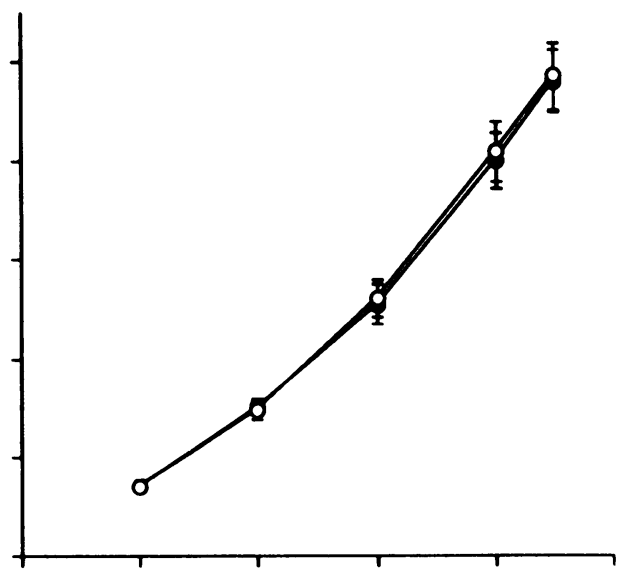

\section{Control group}
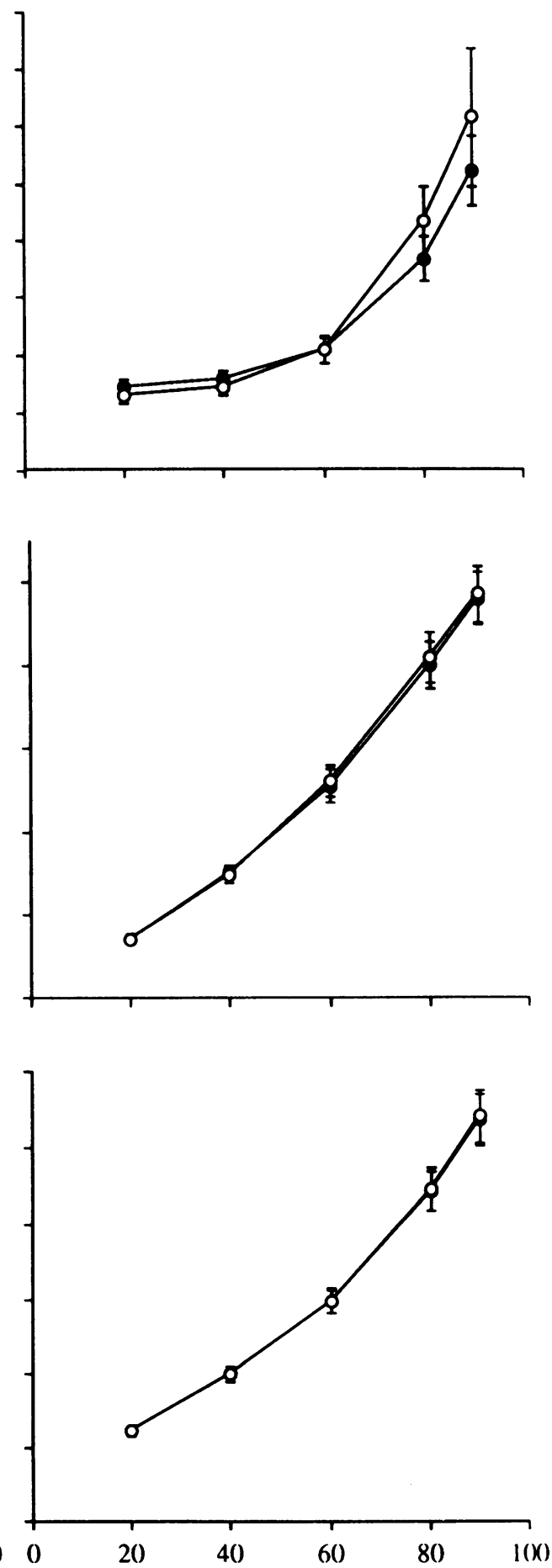

$\dot{\mathrm{VO}}_{2}$ (expressed as \% of initial $\dot{\mathrm{V}}_{2}$ max) 
Figure 2 Relation between perceived breathlessness (Borg rating) and oxygen consumption $\left(\mathrm{VO}_{2}\right)$

(mean) (SEM) expressed as $\%$ of predicted $\mathrm{VO}_{2}$ max 19 before (O) and after $(O)$ the study period for the training and control groups. $\star_{p}<0.05 ; \star \star p p 0.01$ $\star \star \star p<0.001$ (before $v$ after the study).
$\dot{\mathrm{V}}_{2}$

(expressed as \%

of predicted max)

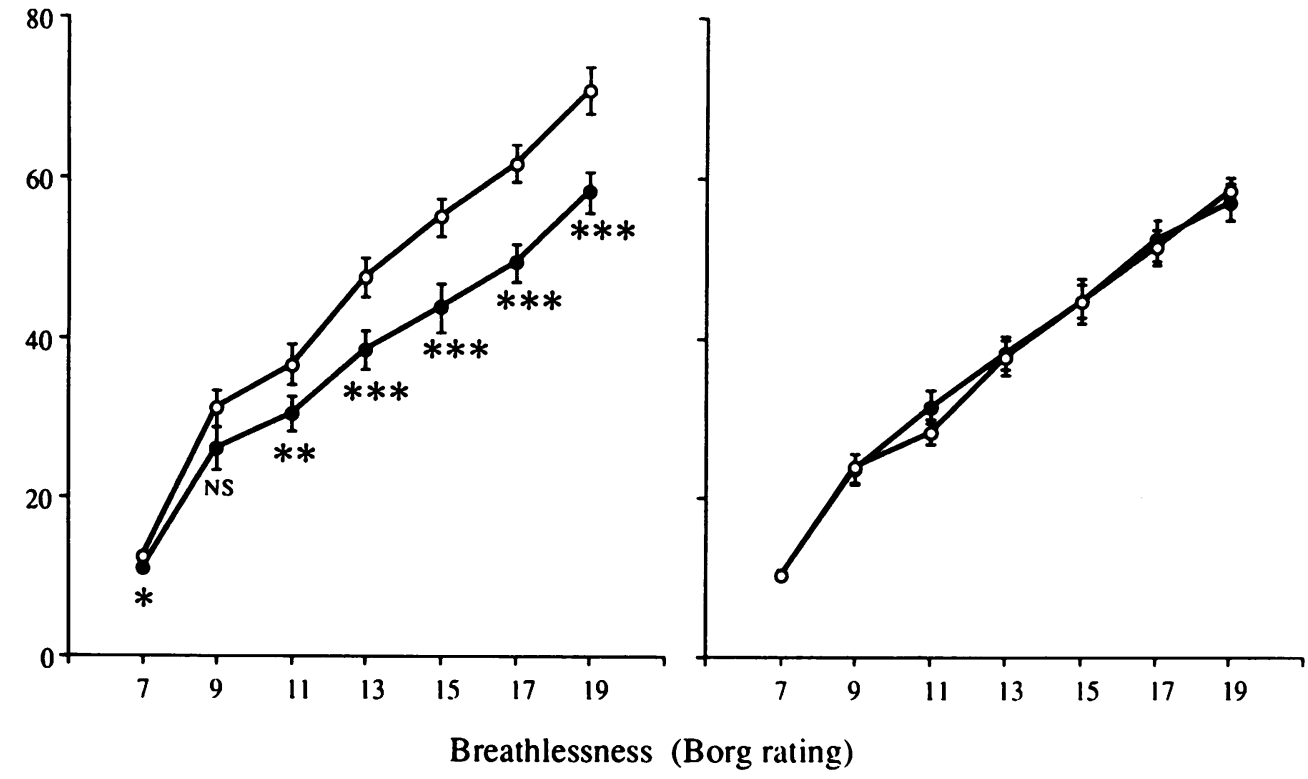

except for the change in maximum heart rate $\left({ }^{\circ}{ }_{0}\right.$ predicted), which was not significant $(-0 \cdot 4(3 \cdot 8)$ and $-1 \cdot 7(3 \cdot 1)$ respectively).

\section{SUBMAXIMAL EXERCISE PERFORMANCE}

The training group showed significant reductions in blood lactate at $80 \%$ and $90 \%$ and in carbon dioxide output, and minute ventilation at $60 \%, 80 \%$, and $90 \%$ of the prestudy $\dot{\mathrm{Vo}}_{2}$ max; there were no significant changes in the control group (fig 1). There was a significant increase in mean $\mathrm{VO}_{2}$ for the training group at all but one level of Borg ratings after the study period (fig 2). The changes in submaximal values differed significantly between the training and control groups for blood lactate at $80 \%$; $\dot{\mathrm{V}} \mathrm{CO}_{2}$ at $60 \%, 80 \%$, and $90 \%$; and $\dot{\mathrm{V}} \mathrm{E}$ at $80 \%$ and $90 \%$ of the prestudy $\dot{\mathrm{VO}}_{2}$ max. At Borg levels 7 and 11-19 the change in $\mathrm{Vo}_{2}$ in the training group was significantly greater than the change in the control group. Linear regression analysis of the relation between heart rate and $\dot{\mathrm{V}}_{2}$ showed a reduction in the mean slope for the training group (before study 0.065 $(0.016)$, after study $0.056(0.009) ; p<0.01)$, with no change in the control group $(0.064$ $(0.019)$ and $0.064(0.020))$.

\section{ANALYSIS OF FACTORS INFLUENCING TRAINING IMPROVEMENTS}

Forty five hospital training sessions were available to each subject in the training group. The mean number of training sessions undertaken by each patient was 36 (range 19-42)-22 (range 8-42) hospital sessions and 14 (range 0 36) sessions at home. The effects of motivation, initial level of fitness, training attendance, and asthma severity and variability on the change in $\mathrm{V}_{2}$ max within the training group were analysed by multiple regression analysis. From this analysis the best model predicting training improvement (that is, percentage change in $\dot{\mathrm{Vo}}_{2} \mathrm{max}$ ) is described in the equation:
${ }_{0}^{\circ}$ change in $\dot{\mathrm{V}} \mathrm{O}_{2} \max =46.9-1.01 \mathrm{sYMP}+$
$6.23 \mathrm{MOT}-0.56 \mathrm{INFIT}\left(\mathrm{r}^{2} 0.80\right.$, SEE 6.66$)$ $6 \cdot 23$ MOT -0.56 INFIT $\left(r^{2} 0 \cdot 80\right.$, SEE 6.66$)$,
here SYMP is the symptom score on the training day, Mот is subject motivation, and INFIT is the initial level of fitness expressed as prestudy $\dot{V}_{2} \max$ (\% pred max).

Once the above three factors had been taken into account, the following failed to reach significance: (1) number of hospital sessions attended; (2) number of home sessions undertaken; (3) total time spent exercising; (4) daily diary symptom score; (5) daily peak flow measurements; (6) coefficient of variation of daily peak flow; (7) coefficient of variation of daily symptom score; (8) prestudy $\mathrm{FEV}_{1}$ (\% pred); (9) prestudy postbronchodilator $\mathrm{FEV}_{1}$ ( ${ }_{0}$ pred); (10) change in $\mathrm{FEV}_{1}$ during the study period (in litres and as percentage change from the prestudy $\mathrm{FEV}_{1}$ ).

\section{Discussion}

Despite the high prevalence of asthma in the population there is a paucity of data regarding the circulatory, ventilatory, and metabolic adaptations to exercise. ${ }^{28}$ The few reported studies have concentrated on childhood asthma and those relating to physical training have often lacked adequate control groups. ${ }^{13-15} \mathrm{We}$ recently identified a very poor level of fitness in young adults with mild to moderate asthma when compared with healthy sedentary individuals. ${ }^{7}$ This appeared not to be directly attributable to the severity of airflow obstruction and thus raised the possibility of a more indirect effect of longstanding asthma in inhibiting exercise and producing aversion to it. That study suggested that ventilatory reserve was adequate to allow sustained exercise at a work intensity sufficient to produce a training effect and we postulated that these patients had the potential to improve their cardiorespiratory fitness. This has been confirmed in the current 
study, as evidenced by the larger increase in $\mathrm{VO}_{2}$ max in the training group than in the controls. This study showed physiological improvements after training not simply in maximal work capacity but also in oxygen delivery throughout submaximal exercise, as reflected by the falls in blood lactate, carbon dioxide output, and minute ventilation in relation to oxygen consumption. These metabolic adaptations to endurance training may be particularly relevant to asthmatic patients. The decrease in ventilation at submaximal work loads is likely to have contributed to the reduction in Borg ratings for breathlessness seen during exercise. ${ }^{29}$ There may also have been a central desensitising effect of the physical training on the sensation of breathlessness during exercise. Rhythmical, repetitive exercise can produce improvements in electroencephalographic synchronicity ${ }^{30}$ and increase endorphin levels without reducing ventilatory chemosensitivity. ${ }^{31} \mathrm{We}$ would draw an analogy between this and the "type II" effects of drugs such as chlorpromazine in reducing breathlessness by a central effect independent of changes in ventilation. ${ }^{32}$ This would be supported by the poor within group correlation between improvements in ventilation and Borg rating after training.

Some comment is required on the changes seen in the control group. There was a slight fall in both maximum heart rate and minute ventilation at the end of the study period. As analysis of submaximal performance showed that there was no significant difference in the relation of heart rate or minute ventilation to oxygen uptake and no significant difference in $\dot{\mathrm{VO}}_{2}$ max, we would interpret these as minor effort dependent changes commonly seen in maximal stress testing. ${ }^{8}$

There is conflicting evidence ${ }^{10-16}$ on the effects of physical training on asthma. We conclude that there is no significant change in underlying disease severity for two reasons: firstly, the improvement in $F E V_{1}$ seen in this study could be explained by an increase in prophylactic treatment in certain patients, particularly as those who had their treatment changed showed the greatest increases in $\mathrm{FEV}_{1}$ (six of those undergoing training had an increase in dosage of prophylactic treatment, compared with three control subjects); secondly, there was no significant change in non-specific bronchial responsiveness. This contrasts with previous studies, ${ }^{1033}$ which showed improvements in exercise induced asthma after physical training. Increasing minute ventilation during exercise is recognised as the stimulus to exercise induced asthma, regardless of whether the mechanism is respiratory heat loss ${ }^{34}$ or increased osmolarity due to respiratory water loss..$^{35}$ Our study suggests that the reported improvements in exercise induced asthma with training may be due to the reduction in minute ventilation seen at high work loads after training (fig 1) rather than a change in underlying bronchial reactivity. Thus the improvement in airflow obstruction in individual patients in our view results from optimisation of treatment arising as an indirect benefit of the continuous medical supervision provided during the programme. Furthermore, optimal treatment is likely to have enhanced their ability to comply with training requirements and highlights the importance of having clinical expertise available during physical training programmes.

Epidemiological studies have identified a relation between the incidence of coronary artery disease and blood lipoprotein concentrations. ${ }^{36}$ It has been suggested that regular exercise may have a favourable effect on blood lipid profiles and hence reduce the risk of cardiovascular disease, though there is no conclusive evidence yet for a direct effect of physical training on blood lipids. ${ }^{37}$ Decreases in body weight and in the percentage of body fat have been proposed as indirect mechanisms for the reduction in lipids seen after physical training. ${ }^{38}$ In this study there was no change in blood lipid profiles, perhaps because we did not control dietary intake, and there was no significant change in body weight. The relation between exercise and lipoprotein concentrations may, however, be more complex in patients with asthma than in normal individuals as impairment of free fatty acid metabolism has been reported in asthma. ${ }^{39}$

The mean increase in $\mathrm{Vo}_{2} \max$ for the group was $24 \%$ of pretraining $\dot{\mathrm{VO}}_{2}$ max values but there was a wide range of improvement, from $1.5 \%$ to $54 \%$. In the multiple regression analysis the change in $F E V_{1}$ secondary to treatment did not contribute independently to the increased $\mathrm{Vo}_{2}$ max, from which we conclude that treatment changes were not responsible for the improvement in exercise performance in the study group. Those who were least fit at the outset of the training gained most in terms of a training effect, as has been reported in healthy subjects. ${ }^{40}$ The motivation score taken early in the introductory period was also highly predictive, despite subsequent education, discussion, and access to medical advice. An initial motivational assessment may therefore save limited resources by identifying potential non-compliers early. The symptom score at the time of training was the third important factor determining training outcome, reflecting not only the severity and variability of asthma but also the inevitable asynchrony between the optimal training condition of the patient and availability of supervised exercise sessions. When subjects had symptoms either they missed the session altogether or the training intensity had to be modified throughout the session. The latter appears to be the more important factor because the correlation between frequency of hospital and home sessions and training outcome did not reach significance in the multiple regression analysis. A practical solution would be to supplement scheduled sessions with home exercise once the patients have been familarised with all aspects of exercise with particular reference to their asthma. These measures would enable patients to undertake exercise during more favourable periods independently of supervised training. Exacerbations may still result in enforced periods of 
reduced activity with consequent detraining, and the exercise supervisor should therefore be aware that these periods are likely to present asthmatic patients with a particularly difficult challenge in terms of their motivation.

This study shows that exercise rehabilitation can bring many improvements in cardiorespiratory performance in asthmatic patients, including a reduction in breathlessness, across a range of work loads equivalent to widely varying daily activities. ${ }^{8}$ We have also identified factors that are important for asthmatic patients in determining the outcome of a physical training programme. Finally, we conclude that continuous medical supervision of training is essential so that the underlying asthma can be monitored, treatment adjusted as necessary, and alternative training strategies evolved during exacerbations.

We are indebted to Allen and Hanburys Ltd for the provision of a clinical research fellowship for L M C at Hairmyres Hospital. We are also grateful to the Chest, Heart, and Stroke Association (Scottish branch) for funding the training programme. We thank Christine Downie for valuable technical assistance; Ann Glen and Inez McKay for preparation of the manuscript, and Dr Nanette Mutrie, assistant director of the Glasgow University department of physical education and sport science, for her contribution to the physical training programme.

1 Anonymous. Look after yourself! London: Health Education Council (78 New Oxford Street, London WC1A 1AH): 1979.

2 Anonymous. Exercise training, fitness and asthma [editorial]. Lancet 1989; i:763-4.

3 Anonymous. The asthmatic child's participation in sports and physical recreation. Pediatrics 1984;74:155-6.

4 Partridge M. Understanding asthma. London: Hawker, 1984

5 Sly RM. Beta-adrenergic drugs in the management of asthma in athletes. J Allergy Clin Immunol 1984;73:680-5.

asthma in athletes. J Allergy Clin Immunol 1984;73:680-5.
Fitch KD, Morton AR. Specificity of exercise-induced asthma. Br Med J 1971;iv:577-81.

7 Clark CJ, Cochrane LM. Assessment of work performance in asthma for determination of cardiorespiratory fitness and training capacity. Thorax 1988;43:745-9.

8 Astrand PO, Rodahl H. Physical training. Textbook of work physiology. 2nd ed. New York: McGraw and Hill, 1977.

9 Clark CJ, Cochrane LM, Clark K, Downie C. A study of the physiological and psychological benefits of jogging in previously sedentary adult women. In: McGregor JA Moncur JA, eds. Sport and medicine. Spawn, London: Spawn, 1986

10 Svenonius E, Kautto R, Arborelius M. Improvement after training of children with exercise-induced asthma. Acta Pediatr Scand 1983;72:23-30.

11 Graff-Lonnevig V, Bevegard S, Erikson BO, Kraepelien S, Saltin B. Two years follow-up of asthmatic boys participating in a physical activity programme. Acta Pediatr ticipating in a physical
Scand 1980;69:347-52.

12 Itkin IH, Nacman M. The effect of exercise on the hospitalised asthmatic patient. J Allergy Clin Immunol 1966; 37:251-63.
13 McElhenny TR, Peterson KH. Physical fitness for asthmatic boys. JAMA 1963;185:142-3.

14 Millman M, Grundon WG, Kasch F, Wilkerson B, Headley $\mathrm{J}$. Controlled exercise in asthmatic children. Ann Allergy 1965;23:220-5

15 Peterson JH, McElhenny TR. Effects of physical fitness program upon asthmatic boys. Pediatrics 1965;32:295-9.

16 Sly RM, Harper RT, Rosselot I. The effect of physical conditioning upon asthmatic children. Ann Allergy 1972; 30:86-93.

17 Hargreave FE, Ryan G, Thomson NC, O'Byrne PM, Latimer $\mathrm{K}$, Juniper EF. Bronchial responsiveness to histamine or methacholine in asthma: measurement and clinical significance. J Allergy Clin Immunol 1981;68: 347-55.

18 Godfrey S. Exercise-induced asthma-clinical, physiological and therapeutic implications. J Allergy Clin Immunol 1975;56:1-17.

19 Jones NL, Campbell EJM. Clinical exercise testing. 2nd ed. Philadelphia: Saunders, 1981

20 Gaensler EA, Wright GW. Evaluation of respiratory impairment. Arch Environ Health 1966;12:146-89.

21 Spiro SG. Exercise testing in clinical medicine. $\mathrm{Br} J \mathrm{Dis}$ Chest 1977;71:145-72.

22 Wasserman K, Whipp BJ, Koyal SN, Beaver WL. Anaerobic threshold and respiratory gas exchange during exercise. J Appl Physiol 1973;35:236-43.

23 Graham TE. The measurement and interpretation of lactate. In: Lollgen $\mathrm{H}$, Mellorowicz H, eds. Progress in ergometry: quality control and test criteria. Berlin: Springer, 1984.

24 Borg G. Perceived exertion as an indicator of somatic stress. Scand J Rehabil Med 1970;2:92-8.

25 Durnin JVGA, Womersley J. Body fat assessed from total body density and its estimation from skinfold thickness; measurements on 481 men and women aged from 16 to 72 years. Br J Nutr 1974;32:77-97.

26 Tsanakas JN, Bannister OM., Boon AW, Milner RDG. The "Sport-tester": a device for monitoring the free running test. Arch Dis Child 1986;61:912-4.

27 Knudson RJ, Slatin RC, Lebowitz MD, Burrows B. The maximal expiratory flow volume curve. Am Rev Respir Dis 1976;113:587-600.

$28 \mathrm{McF}$ adden ER. Exercise performance in the asthmatic. $\mathrm{Am}$ Rev Respir Dis 1984;129:584-7.

29 Cockcroft A, Adams L. Measurement and mechanisms of breathlessness. Bull Eur Physiopathol Respir 1986;22: 85-92.

30 Fernal B, Daniels FS. Electroencephalographic changes after a prolonged running period. Evidence for a relaxation response [abstract]. Med Sci Sports Exerc 1984; 16:181.

31 Mahler DA, Cunningham LN, Skrinar GS, Kramer WJ, Colice GL. Activity and hypercapnic ventilatory responsiveness after marathon running. J Appl Physiol 1989; 66:2431-7.

32 Stark RD. Dyspnoea: assessment and pharmacological manipulation. Eur Respir J 1988;1:280-7.

33 Henriksen JM, Nielsen TT. Effects of physical training on exercise-induced broncho-constriction. Acta Paediatr Scand 1983;72:131-6.

34 Deal EC, McFadden ER, Ingram RH, Strauss RH, Jaegger JJ. Role of respiratory heat exchange in production of JJ. Role of respiratory heat exchange in production of

35 Sheppard D, Eschenbacher WL. Respiratory water loss as a stimulus to exercise-induced broncho-constriction. a stimulus to exercise-induced bron

36 Noma A, Yokosuka T, Kitamura K. Plasma lipids and apolipoproteins as discriminators for presence and severity of angiographically defined coronary artery disease. Atherosclerosis 1983;49:1.

37 Goldberg L, Elliot DL. The effect of physical activity on lipid and lipoprotein levels. Med Clin North Am 1985; 69:41-45.

38 Quig DW, Thy FW, Ritchey SJ, et al. Effects of short-term aerobic conditioning and high cholesterol feeding on plasma total and lipoprotein cholesterol levels in sedentary young men. Am J Clin Nutr 1983;38:825.

39 Barboriak JJ, Sosman AJ, Fink JN, Maksud MG, McConnell LH, Hamilton LH. Metabolic changes in McConnell LH, Hamilton LH. Metabolic changes

40 Wenger HA, Bell GJ. The interactions of intensity, frequency and duration of exercise training in alterin cardiorespiratory fitness. Sports Med 1986;3:346-56. 